\title{
At the Time of Writing: Sedgwick's Queer Temporalities
}

\author{
ANNA GIBBS
}

This essay, written 'after Sedgwick', in no way attempts to imitate her inimitable writing, but operates, rather, in the wake of her work, drawing together some of the concerns that animated it-queer theory, affect theory, and literary performativity - and drawing on it, perhaps obliquely, to address an unlikely text, Jane DeLynn's Don Juan in the Village. It's an unlikely text because it is seems in many ways too obvious (since it deals explicitly with lesbian sexuality and with the affects of shame and disgust and therefore can't possibly require 'queering'), and it's unlikely, too, because specifically lesbian fiction is so rarely taken to make present and palpable something of the politics of queer, never mind the politics of the literary tout court. On the other hand, though, Sedgwick's work amply legitimates such a perverse textual choice.

If the phrase 'at the time of writing' means now, in the present moment, it also suggests a qualification, the possibility that things may be different at some other time, in a future simultaneously anticipated and unanticipated. It is this aporia that renders conformity to certain theoretical routines futile, and that challenges writing to remain 'live' - alive to the unexpected spark that comes from a disruptive glitch in the smooth taken-for-grantedness of the self or social. This might take the form of the temporal disorientation brought about by the contingencies of queer lives such as those Sedgwick describes, in which the singular relationship to the succession of generations makes it clear that yesterday differs from today and tomorrow (Novel Gazing 26). Or it might more actively be brought about by a work of queer reading attuned 'exquisitely to a heartbeat of contingency' (25) and performed in a writing adequate to the moment in which identification 'falls across gender' and 'falls no less across sexualities, across "perversions"' (Sedgwick, Touching Feeling 257). This process we now term 'queering' might once, in traditional English departments, have been called 'perversion', in the sense of unwarranted caricature, distortion, falsification, twisting or slanting (to cite the terms my desktop thesaurus offers as synonyms). If such work is now warranted by virtue of its articulation as a rhetorical method, it remains crucial not to forget the sexual sense of 'perversion' suppressed by my thesaurus - no doubt because of its history as a term of derision. It is crucial, likewise, to refuse to allow the term 'queer' to be completely detached from the marginalized sexualities and the very 
particular political contestations which have revivified it as a 'reverse discourse' (Foucault 101). For to allow this detachment would mean that 'queering' is no more than a metaphor for operations that may have nothing whatsoever to do with marginalized sexualities or those of us whose lives are still in many ways defined by them. But nor should it simply be reduced to them. Sedgwick's work makes clear that, if queer is always 'relational' to other flows, it cannot simply be assumed to exist but requires constant reinvention by a performative process - in which bodies are at stake - in the liveness of the here and now that is reading, as well as writing.

If some feminist theories of performativity in the wake of Sedgwick's work, and indeed Shoshana Felman's The Scandal of the Speaking Body (the translation of which from the French was first published as The Literary Speech Act), have sometimes seemed to disavow the materiality of bodies, Terry Threadgold suggests that one possible antidote to this tendency would be to explore the complex ways in which bodies and texts fold into one another, crafting and shaping the materiality of [both] texts and of bodies' (Threadgold). Sedgwick's particular commitment to the literary was, I think, an attempt to do just this: after all, it was an experience of reading (Proust) that introduced Sedgwick to the queer possibilities her work went on to bring into being (Epistemology). Now, in a context in which the literary has supposedly been rendered redundant by digital media and popular culture, it seems important to stress that literary reading is not only a site for critical work on and in language, through which we may discover the way language works us as we work it, but that literary writing in whatever medium also does that work - because literature, as Roland Barthes once put it 'performs language rather than merely using it' (Leçon 19; my translation). It is through 'literary writing [écriture], [that] knowledge reflects incessantly on itself, by virtue of a discourse which is not epistemological, but dramatic' (19). What this means is that bodies must always be at stake in it, since it requires that we give ourselves wholly over to active imaginative participation in it (at least at one stage of reading), rather than remaining at a detached and disinterested critical distance.

Fiction, after all, demands a visceral involvement, one that challenges the fixity of our own bodily limits. To read fiction at all is to lend our body to alien affects, and to allow ourselves to be possessed by them. Fiction solicits our affective energies and draws them into worlds of story for which it also requires a certain suspension of cognitive disbelief - that is, a willing belief in the face of knowledge to the contrary - a process known to psychoanalytic thought as disavowal. Fiction is, as Roland Barthes has it, the locus par excellence of disavowal, disavowal being, of course, the very badge of perversion. Arguably, all fiction is also contractual-another symptom of perversion, for it too is solicitous of an intimacy that is designed rather than spontaneous, although of 
course neither meaning nor reading can ever be fully controlled or predicted, and this sets the stage for precisely the kind of contingency that queer readings will seize. We might even argue that fiction, both the writing and the reading of it, is an everyday perversion, and in so arguing, we see that perversion lies at least potentially within us rather than safely without. We can no longer disown perversion by projecting onto the other, whom we designate as 'pervert'. And here we glimpse what Freud (as against the sexologists such as Krafft-Ebing and Havelock Ellis) saw: that perversion is a general state of affairs and so-called 'normality' a special case, often violently imposed.

For this reason, as well as because of its direct hold on the body, fiction may be, if not exactly a privileged, at least an important site for the explorations of queer theory. Especially so, perhaps, in its need to work with, as well as against, the fictions of the subject, among which I include the experience of the self which forms part of the culture of absorption - as opposed to what Margaret Morse has termed the 'culture of distraction' - to which fiction belongs. ${ }^{1}$ Arguably, we are now starting to see another alternative emerge in new media cultures which remediate the literary but which also give rise to different forms of attention, different techniques of memory and different dispositions of the body-and with them, new, emergent forms of subjectivity. This argues a need to be alive to subjectivity as a process rather than a given. While there is a powerful line of thought that would want to dispense altogether with subjectivity as a foundation for queer theory (e.g. Lauren Berlant), Sedgwick's work rather insists on troubling and unsettling subjectivity above all by insisting on both its contingency and its relationality. This enables her to avoid its reification as a category, while still charting trajectories born of the moments where subjectivity exceeds what is normative in that particular moment. And it is this that qualifies her work as an ethical project.

Central to the experience of the self-perhaps especially in the culture of interiority and the politics of identity to which it has given rise-is the affect of shame. But shame is also what might shatter the plenitude of the self on which interiority and identity both depend. Shame is the site at which the question of identity arises more originarily, and most relationally', according to Sedgwick ('Shame in the Cybernetic Fold' 239). Shame arises, according to Silvan Tomkins (to whose work Sedgwick and Adam Frank introduced queer theory and the humanities more broadly) at the precise moment when interest in, excitement about, or enjoyment of communion with the other is suddenly interrupted. Although of course one can feel shame at something remembered, or imagined, shame is prototypically relational in origin: it is a social affect in a way that fear or distress or interest are not. Paradoxically, shame produces

1 According to Morse, the culture of distraction includes the contemporary experiences of driving on the freeway, spacing out in the shopping mall, and watching television. 
searing consciousness of self at the very moment it threatens to dissolve that self completely. For that reason, the struggle between shame and the self has often been represented as a fight to the death: 'She would have thought a woman would have died of shame. Instead of which, the shame died'. Such is the experience of D.H. Lawrence's Constance Chatterley (258), harbinger of the discourse of sexual liberation movements that envisaged shame as something from which we could be freed. But for Sedgwick this is an impossible project, because even the 'affirmative reclamation' that makes 'queer' into a reverse discourse will never 'succeed in detaching the word from its associations with shame and with the terrifying powerlessness of gender-dissonant or otherwise stigmatized childhood' ('Queer Performativity' 4). Perhaps it's the case that that this is now less true for some (young, white people living in cities like Sydney or San Francisco, for example) than for others, but in any case Sedgwick's work finds a use for shame precisely because of the threat it poses to the subject who finds herself overcome by it. Yet to work on shame, and with shame, in the face of the politics of pride is a risky process. If shame tends to concealment and the cryptic, pride, on the contrary, calls for revelation and display. But not the revelation of shame. Shame, as Tomkins points out, is itself shameful and by virtue of that, reluctant to speak its name.

Perhaps it is not by chance that if Sedgwick is the cartographer par excellence of the complex convolutions of shame in theoretical writing, her counterpart in fiction should be a lesbian writer, Jane DeLynn, whose work has been little addressed by scholarly writing, perhaps because it coincides with the very moment when, as Sedgwick points out, the politics of pride have become reflexive. ${ }^{2}$ But DeLynn's work is not anachronistic: it is writing post-Pride, writing that unfolds a landscape of the unspoken and the unspeakable concealed in the cracks of visibility and revelation. DeLynn is a New York writer and author of five novels, several works for theatre, and many short stories. Her fourth novel, Don Juan in the Village, was published in 1990, and it is from this book that the story 'Butch', on which I will focus here, is taken. The fifth - in some ways a sequel to Don Juan - Leash, was published in 2002.

Don Juan is a lesbian and the village in question is Greenwich Village in the late seventies. The novel is really a series of discrete episodes linked by the self-examination of their first person narrator who engages, with far more scientific curiosity about her own feelings and the meaning of her actions than her namesake, in a series of sexual encounters which essentially comprise a quest for amatory perfection that part of her knows is illusory. The original Don Juan figure was, of course, the masculine enumerator of sexual conquests who

2 Guy Davidson's essay, 'Bar and Dog Collar: Commodity, Subculture, and Narrative in Jane DeLynn' is not only an exception to this silence, it also adduces an excellent analysis of other reasons why this might be the case. 
prided himself precisely on his lack of feeling, though not of pleasure. Don Juan uses women, but, as DeLynn points out in an interview with Noel King, 'the question of who uses whom in a sexual relation is much more complicated than most people allow' (King 1). ${ }^{3}$ Married women may use Don Juan to relieve their boredom - single women, however, risk having their reputations (and hence their livelihoods) ruined in the context of the sexual inequality in which the original stories are situated. In any case, who uses whom is much at issue in the episodes narrated by DeLynn's female Don Juan, just as the 'use' of other people as objects is one of the symptoms of 'perversion' in psychoanalytic discourses on the subject. These discourses, of course, classically assume that perversion is a masculine characteristic, built around the disavowal of the maternal phallus. More recently, Estela Welldon and Louise Kaplan have both argued that female perversion consists of the use of the pervert's own body (or possibly that of her child), rather than the use of a sexual partner (anorexia or self-harm of some other form would be paradigmatic here).

DeLynn's Don Juan, however, is not interested in self-harm but in self-knowledge, and her mimicry of her masculine namesake affords her identification not only with heterosexual men's relationships with women, but also with gay men's lifestyles, at least as they are glimpsed-or imagined-by the narrator. The epilogue of the book, entitled '1988' and written as retrospective reflection on the seventies, meditates on the distance between 'then' and 'now'. The 'then' in question - which, as DeLynn says in an interview, is like an old photograph, instantly acquiring 'a certain nostalgia' (King 2)-maps the period of the narrator's youth onto an essentially gay male pre-AIDS age of innocence:

Now the baths are closed, the pier has long since been torn down, and with the revellers of those bright days so too my envy has gone. Hot nights for men now consist of circle jerks; many of the former 'sluts' are chaste. I, myself, as the song says, don't get around much any more.

(Don Juan 240)

In 'Butch', the narrator brings home the ugly, thin, pale, battered girlfriend of a 'real' butch who in turn steps into the butch role vis-à-vis the narrator. This woman, Laura, is desired by the narrator precisely because she (Laura) disgusts her, and because under these circumstances (in which the narrator is 'obviously' the more attractive partner) the narrator feels 'no obligation' (nor apparently any desire) to take any sexual initiative or to be anything but passive. The narrator minutely observes her own reactions as Laura proceeds to tie her up, leaving her hands bound and a dildo up her arse when she eventually departs. For some readers, this material alone is sufficient to arouse both embarrassment

3 My thanks to Noel King for allowing me access to the complete unpublished version of the interview. Page numbers refer to the manuscript, not to the published version. 
and disgust. ${ }^{4}$ But for others, it is not so much the sexual relations as the power relations played out through them that give offence. For feminist readers this is at least in part because these power relations seem to mimic certain heterosexual forms. At first, for example, the narrator is in a commanding position: she makes the woman, Laura, walk behind her 'like Chinese women used to do' (225) so no one will see them together. But the narrator's own redoubled shame immediately undermines her authority in the eyes of the reader: she tells the woman that it's because she doesn't want to be seen with a woman, rather than the truth, which is that it's because she doesn't want to be seen with her in particular, because she is ugly. The narrator's admissions, however, are not made in a confessional tone as if to elicit forgiveness, or even judgment. Rather, she is matter-of-fact, and seems to assume that her readers will be familiar with the kinds of feelings, and perhaps even the kinds of behaviour, she describes in herself. It is this fact that seems to affront some readers, provoking them to expressions of disgust at the thought of being assumed to identify with something abhorrent. While some readers might laugh in tacit admission of at least a grain of truth here, others, feeling themselves exposed, compromised, even contaminated, and wanting to distance themselves from the object of their disgust, will sometimes rationalise their response to the story on either feminist or clinical grounds. On the latter grounds, they might point to the classically masochistic behaviour of the narrator, who, for example, fails to put on more music, calculating that the silence will force Laura to make the first move (passive aggression), and that this will then free the narrator of responsibility for whatever happens between them (denial). In fact, though, 'perversion', so-called, when it appears in literary contexts, it is often designed to shock, and to produce, precisely, horror and disgust. This disgust response is legible in psychoanalytic writings on perversion, which often fall back on ideas of analytic neutrality or otherwise evince a need to keep a safe theoretical distance from the object that provokes it. Janine Chasseguet-Smirgel - to cite only one of the most well-known writersmanifests such disgust by her generalisation that 'perverts lie', that they are 'deceptive' (34). The strength of disgust responses to perversion hints at the threat the pervert poses to the normative, and points to the need to maintain this distance, to remain uncontaminated or uncorrupted - that is, in the case of readers of DeLynn, unchanged by the encounter that is reading, especially the reading of a literary text.

Readers who respond to disgust with a reflexive desire for distance at all costs tend to miss the humour that Gilles Deleuze identifies in masochism (which he casts in the masculine). He points out that the masochist, feeling the Law to be inherently punitive, applies its punishment to himself in his punctilious

4 I have discussed this story at different times with students of writing, members of a feminist reading group, and at a conference of mental health professionals (psychologists, psychiatrists, and psychoanalysts) and interested academics. 
observation of the letter of the Law, making apparent its consequences, which are often absurd, the opposite of what was intended (for example, whipping induces erection). The masochist, he writes, is 'insolent in his obsequiousness, rebellious in his submission; in short, he is a humorist, a logician of consequences' (Deleuze 89). While sadism entails an ascent to principle and militates against the Law by irony and subversion, the masochistic ruse of apparent submission and its descent to consequences, to the detail of 'dirt under the fingernails', instead flouts the Law by means of humour, specifically, the reduction to the absurd. Indeed, DeLynn's narrator, eyes closed, hears the sound of Laura flushing the toilet, listens for the sound of the faucet (which she doesn't hear), and worries about germs. And, in fact, neither a clinical diagnosis nor a feminist analysis of the narrator's perversion would tell either her or the reader anything we don't already know: the point of the story is that there are no psychological depths to be discovered, since the narrator is the consummate anatomist of her own self-deception.

It is this painstaking attention to detail that allows the narrator to chart the way the power relations she describes come to shift, so that when Laura does begin to take the initiative, the yearning she arouses in the strategically passive narrator becomes anger that she is apparently being teased, and she observes that 'oddly, the angrier I got, the more my respect for her grew' (229). As the sex progresses the narrator comes to feel that 'things were more in balance than earlier in the evening' (230), until, by the end of the story the tables have been turned and narrator's mimicry of submission has become real. Just as important as this reversal, though, is the narrator's tracing of the vicissitudes of the excruciating self-consciousness which prevents her from ever being wholly with anyone - much in the way a certain self-consciousness seems to prevent some readers being wholly present to the story. In the scarifying sharpness of its contours, the narrative is a map of the 'psychic skin' turned inside out. 'Skin side out' is, of course, one of the names for shame (Sedgwick, Touching Feeling 38 ), and points to the fact that both the boundedness and the autonomy of the self are at stake in it.

However, it is not on the moment of being flooded with and overwhelmed by shame that DeLynn concentrates. Rather, 'Butch', like all the stories in Don Juan in the Village, charts the trajectories by which shame increases and becomes mobile and by which it seeks concealment. It is characteristic of shame (as of all affects, according to Tomkins) that it forms positive feedback loops in which more of the same affect is created - that is, shame amplifies or intensifies itself as we receive feedback from our own blushing. Shame also tends to 'magnify' itself, 
in Tomkins' terminology (Vol. 3), so that recalling one episode of shame tends to call up memories of others, until the self is overwhelmed and momentarily disappears, as if it had been swallowed by shame. ${ }^{5}$

This tendency of shame to reproduce itself and to extend its purchase from site to site as awareness of its possibility grows and the need to forestall it becomes more and more pressing, is exactly what DeLynn's fiction maps, and at one level the reader may go with the flow of identification with the first person narrator, and with the inevitable cascade produced by the mobility of shame, as it transfers itself from one situation to another. DeLynn's narrator seeks out intensity in order to feel real, but at the same time it seems that intense affect threatens her sense of control. If this is her problem, it is also the reader's problem as we are drawn in by the identificatory intimacy solicited by the first person narration but compromised by what it reveals. For 'Butch' does indeed compel experience of the very affects that will call into question, and then sharply define, the limits of the self. Disgust and shame, but not anger or fear or distress, are, as Adam Frank writes,

affects that for formal reasons are particularly well-suited to the activation of a theoretical frame ... that punctuates a system as distinct from its environment [and which] permit the system to make certain kinds of critical distinctions: about what should or should not be brought into, made a part of, or made otherwise perceptible for the system. (30)

For DeLynn's narrator, disgust may be a way of testing her own limits, of seeing how far she'll go, of mapping her own boundaries, or perhaps of giving herself the thrill of surprise. For the reader, disgust marks the moment we may have been contaminated. We have been taken in by - and by the same token have taken in, ingested - the disgusting object. There is no guarding against this when one is reading, for, unlike shame, the possibility of which causes excruciating anticipation, disgust always takes us by surprise. Even if one expects it at an intellectual level in the face of, say, a corpse, or one fears it going in to watch a horror movie, the affect itself, its viscerality, is always new. Having been disgusted, we have been compromised - our nausea is the symptomand to regain our equilibrium we seek the distance afforded by reflection, for it is precisely aesthetic distance that disgust has temporarily destroyed. As Menninghaus reminds us, disgust has been thought of

5 'Magnification', in Tomkins' vocabulary, refers to the way in which having been sensitised to an affect, the subject may then tend to scrutinize the environment for potential sources of the same affect in order to avoid it - but in so doing, makes that affect even more salient in his or her world. See Tomkins, Affect Vol. 3. 
as a 'dark' sensation that so categorically indicates something 'real' that it strains the distinction between 'real' and 'imaginary' — and therewith the condition for the aesthetic illusion: I am disgusted-therefore $I$ experience something as unconditionally real (not at all as art). (9)

It may be that this is the reason why DeLynn's fiction hasn't been much addressed in scholarly writing, queer or otherwise: not only is its exposure of the reader to her own shame unbearable, but the feelings of disgust it solicits in part by way of defence against shame may be an obstacle to the kinds of rhetorical analysis performed by queer theory because in the moment of disgust, the reader forgets that what she is reading is fiction, and that what has produced the feeling of disgust has in fact been staged, and staged precisely to produce disgust.

For DeLynn's narrator, affect - especially negative affects like disgust - is the source of knowledge. But not, as it turns out, transcendental knowledge. Rather, with hindsight, knowledge is exposed as limited, practical and site-specific: 'I had come to the bar for knowledge, but it turned out that that knowledge was only about how to behave in bars such as this' (241).

Now perversion is thought as the sexualisation of what would not ordinarily be sexual; for example, when punishment for transgression is sexualised, as when, classically, schoolboys who have been flogged - in reality or in fantasybecome masochists. The narrator does enjoy the (moderate) physical pain the 'butch' inflicts on her, but on the whole, 'pain' in DeLynn's stories means the 'punishing' qualities of the negative affects, ${ }^{6}$ especially anguish and the feelings associated with it: sadness, despair, loneliness and all aspects of the tragic, as reflected in the country and western music the narrator listens to some time after the butch has left and she has finally freed her own hands and removed the dildo from her arse. Thinking about the strange sadness she feels, she realises that 'It was the same sadness that was always there, and it occurred to me that I must like it. Why else did I keep going to bars, if not to find it?' (241).

If sadness turns out after all to be romantic, even sophisticated, the narrator is nevertheless hyper-aware of the need to avoid shame. Shame itself, as Tomkins points out, is shameful, and the feedback loop created by it is precisely what creates the feeling of vertigo it induces as the self disappears into it. Shame is the secret affect: a blush may betray it, but it resists articulation, and for this reason it often generates 'strong' theories and strategies of avoidance. DeLynn's narrator has a strong shame theory: that is, sensitised to the prospect of shame, she finds the possibility of it everywhere she turns her attention, even when it is to just such strategies of avoidance:

6 Tomkins explains that positive affects are designed to be rewarding, to make us want to prolong them, or to produce them again, while the negative affects are designed to be punishing in order to make us want to avoid them or put an end to the state of affairs producing them (Affect Vol. 1). 
It could be a worry about how much to tip the cabdriver in the presence of someone you're hoping to go to bed with, how to hold a glass of beer or whether to drink from the bottle when you're cruising in a bar. Or it could be a worry about making a noise pissing in the toilet, therefore pulling off wads of toilet paper to conceal that noise, only to then worry that the noise of pulling off wads of toilet paper will draw people's attention anyway. (King 3)

Or, as in 'Butch', the worry is about farting in the midst of sex. It has been said that there are only three possible responses to shame: run, hide, or die. But the very intensity of the need to avoid shame may also provoke a fascination with it (if not a sexualisation of it) and what brings it about. For example: the experience of abjection generated by one's own contamination from proximity to what is disgusting. As DeLynn has said:

I think there is some connection between attraction and revulsion. Not always, but in certain kinds of ways and perhaps more so when one is in an extreme state, say involving drugs or alcohol. It's then that you maybe can allow yourself to be attracted to the abominable. It has a charge and, in a way, a charge is better than nothing. Or it could be curiosity. (King 4)

Perhaps the curiosity about which DeLynn speculates here is the perversity of one's own desire in the face of what is socially acceptable. The sudden reversibility of desire and disgust may suggest that what is most disgusting will provoke the most intense pleasure. Perversion, as psychoanalysis has thought it, does entail a valorization of the unvalued, and a concomitant devaluing of what is commonly valued. In fact, this reversal of value has provided an important strategy in queer engagements with the world, from Roland Barthes' sexual/ textual plays on 'inversion' to Edmund White's discussion of gay life in the Granta issue on 'Shrinks', and it provides the foundation of the camp aesthetic as counter-discourse. As DeLynn says:

I think a gay sensibility is about being 'perverse' - not necessarily sexually perverse, but perverse in relation to whatever the prevailing norm is considered to be. Like, what would be perverse in the gay community now would be totally vanilla sex. It's a constant saying 'no' to everything - rather than saying 'yes' to anything. (King 21)

DeLynn's narrator takes perversity as a life strategy, valorizing homosexuality, and, by extension, perversion of all kinds, over 'normality', and pain, including the psychic pain of shame, over pleasure. Except, perhaps, the pleasure of writing the shame that should not speak its name. 
In her essay on paranoid reading, Sedgwick comments on the privileging of the negative affects in queer politics, especially as they coalesce into a paranoid attitude or posture. It is, she says, the raison d'être of the ' $\mathrm{x}$-ray gaze' of the paranoid posture to 'see through to an unfleshed skeleton of the culture; the aesthetic on view here is one of minimalist elegance and conceptual economy' (Touching Feeling 139.) But one of the problems of the paranoid gaze is that it always overlooks its own position, which it situates outside the problem it claims to diagnose by virtue of its capacity for mastery or its special insight. Above all, the paranoid reading seeks to claim the high moral or political ground, and this is why it can never afford a sense of humour. The very transparency of DeLynn's writing with its shameless anatomy of shame resists paranoid reading and works to undermine the very idea of any high moral ground by its leveling humour.

In the end, the narrator's mix of irony and nostalgia about her younger self makes us laugh - with her, not at her. We, like her, secretly know ourselves to be 'the most incredible human being in the world' (Don Juan 243), and DeLynn has found us out. But the other, shadow sense of 'incredible' ('pathetically unbelievable') is also secretly at work here. The flipside of the narrator's (and our) belief in our brilliance is the secret, shameful knowledge that we are, in fact, the worst human being in the world. What the vertiginous ironies of 'Butch' repeatedly make us perform is the rediscovery of the way in which we are actually implicated and involved in what is known, which lies, as Shoshana Felman long ago pointed out in an essay on the nature of teaching, at the heart of the analytic enterprise, as it does of fictional engagement. (Felman points to the myth at the heart of the analytic fiction, the story of Oedipus, who cannot see his own involvement in the text of his own story as he narrates it to himself (44).) 'Butch' doesn't just tell us that we, as readers of fiction, are as perverse as its narrator. Nor does it simply make us feel perverse. It rather makes us perform an act of attempted mastery over the sensate experience of story, and then reveals this mastery for the-perverse-fiction it is.

Anna Gibbs is Associate Professor in the School of Communication Arts at the University of Western Sydney. She has published across the fields of creative arts and textual, media and cultural theory. Her current research projects are on affect, sympathy and mimesis; art (and) writing; and, with Maria Angel, writing and the body in the new media arts. 


\section{Works Cited}

Barthes, Roland. Leçon. Paris: Seuil, 1978.

—. Sade, Fourier, Loyola. Trans. Richard Miller. New York: Hill and Wang, 1976.

Berlant. Lauren. 'Two Girls Fat and Thin.' Regarding Sedgwick: Essays on Queer Culture and Critical Theory. Ed. Stephen M. Barber and David L. Clark. New York: Routledge, 2002. 71-116.

Chasseguet-Smirgel, Janine. Creativity and Perversion. London: Free Association, 1985.

Davidson, Guy. 'Bar and Dog Collar:

Commodity, Subculture, and Narrative in Jane DeLynn'. Genders Online Journal 51 (2010). <http://www.genders.org/g51/g51_davidson.html> Accessed 30 Mar. 2010.

Deleuze, Gilles. 'Coldness and Cruelty.' Masochism. New York: Zone, 1989. 7-138.

DeLynn, Jane. Don Juan in the Village. New York: Ballantine, 1992.

Felman, Shoshana. The Scandal of the Speaking Body. Stanford: Stanford UP, 2003.

—. 'Psychoanalysis and Education: Teaching Terminable and Interminable.' Yale French Studies 63 (1982): 21-44.

Foucault, Michel. The History of Sexuality: Volume 1, An Introduction. London: Random House, 1978.

Frank, Adam. 'The Letter of the Laugh.' Poe Studies/Dark Romanticism 33: 1-2 (2000): 29-32.

Kaplan, Louise. Female Perversions: The Temptations of Emma Bovary. New York: Doubleday, 1991.

King, Noel. 'Interview with Jane DeLynn.' Unpublished manuscript. Extract published as Jane DeLynn, 'Sentences that Lead Me Someplace,' Island Magazine 60-61 (1994): 12-19.

Lawrence, D.H. Lady Chatterley's Lover. Harmondsworth: Penguin, 1974.

Menninghaus, Winfried. Disgust: Theory and History of a Strong Sensation. Trans. Howard Eiland and Joel Golb. Albany: SUNY, 2004. 
Morse, Margaret. 'An Ontology of Everyday Distraction: The Freeway, the Mall and Television.' Logics of Television. Ed. Patricia Mellancamp. Bloomington, Indiana University, 1990. 193-221.

Sedgwick, Eve. Epistemology of the Closet. Berkeley, U of California P, 1990.

—. Novel Gazing: Queer Readings in Fiction. Durham: Duke UP, 1997.

—. 'Queer Performativity: Henry James's The Art of the Novel.' GLQ 1 (1993): $1-16$.

—. Touching Feeling: Affect, Pedagogy, Performativity. Durham: Duke UP, 2003.

Threadgold, Terry. 'Cultural Studies, Critical Theory and Critical Discourse Analysis: Histories, Remembering and Futures'. Linguistik online 14 (2003). $<$ http://www.linguistik-online.com/14_03/threadgold.html > Accessed 6 May 2010.

Tomkins, Silvan S. Affect, Imagery, Consciousness:The Positive Affects (Vol. 1). New York: Springer, 1962.

—. Affect, Imagery, Consciousness: Anger and Fear (Vol. 3). New York: Springer, 1991.

Welldon, Estela. Mother, Madonna, Whore: The Idealization and Denigration of Motherhood. New York: Guilford, 1984.

White, Edmund. 'Shrinks.' Granta 71 (2000): 61-89. 